\title{
Dual Fluidized Bed Biomass Gasification
}

Final Report for Base Program Task 1A Under DE-FC26-98FT40322

September 2005

\author{
U.S. Department of Energy \\ National Energy Technology Laboratory \\ Morgantown, West Virginia
}

By

Western Research Institute

Laramie, Wyoming 


\section{DISCLAIMER}

This report was prepared as an account of work sponsored by an agency of the United States Government. Neither the United States Government nor any agencies thereof, nor any of its employees makes any warranty, expressed or implied, or assumes any legal liability or responsibility for the accuracy, completeness, or usefulness of any information, apparatus, product, or process disclosed or represents that its use would not infringe on privately owned rights. Reference herein to any specific commercial product, process, or service by trade name, trademark, manufacturer, or otherwise does not necessarily constitute or imply endorsement, recommendation, or favoring by the United States Government or any agency thereof. The views and opinions of authors expressed herein do not necessarily state or reflect those of the United States Government or any agency thereof. 


\begin{abstract}
The dual fluidized bed reactor is a recirculating system in which one half of the unit operates as a steam pyrolysis device for biomass. The pyrolysis occurs by introducing biomass and steam to a hot fluidized bed of inert material such as coarse sand. Syngas is produced during the pyrolysis and exits the top of the reactor with the steam. A crossover arm, fed by gravity, moves sand and char from the pyrolyzer to the second fluidized bed. This sand bed uses blown air to combust the char. The exit stream from this side of the reactor is carbon dioxide, water and ash. There is a second gravity fed crossover arm to return sand to the pyrolysis side. The recirculating action of the sand and the char is the key to the operation of the dual fluidized bed reactor. The objective of the project was to design and construct a dual fluidized bed prototype reactor from literature information and in discussion with established experts in the field. That would be appropriate in scale and operation to measure the relative performance of the gasification of biomass and low ranked coals to produce a high quality synthesis gas with no dilution from nitrogen or combustion products.
\end{abstract}




\section{TABLE OF CONTENTS}

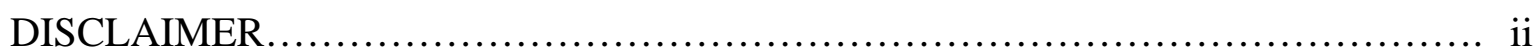

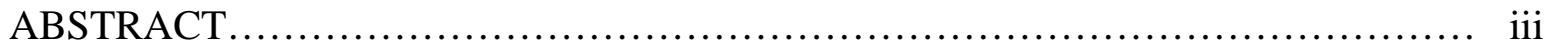

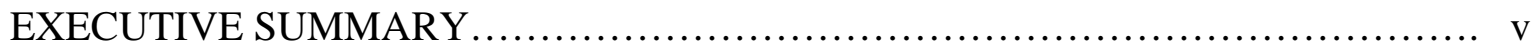

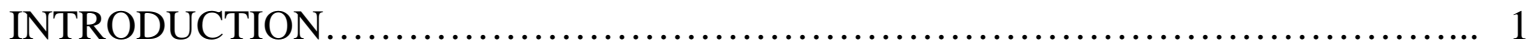

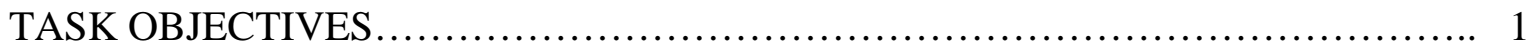

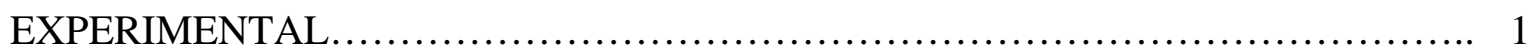

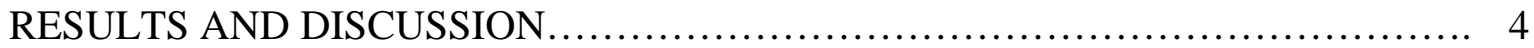

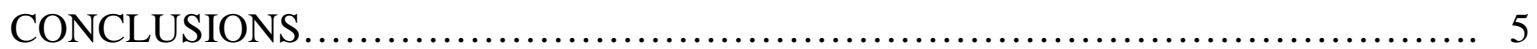

REFERENCES............................................................. 5

\section{LIST OF FIGURES}

1. A cold flow model of a dual fluidized bed was produced to test transport of the fluidizing material between the two beds.................................. 2

2. The stainless steel working dual fluidized bed prototype...................... 3

3. The working prototype and associated support systems with the heating elements removed. 


\section{EXECUTIVE SUMMARY}

The dual fluidized bed reactor is a recirculating system in which one half of the unit operates as a steam pyrolysis device for biomass. The pyrolysis occurs by introducing biomass and steam to a hot fluidized bed of inert material such as coarse sand. Syngas is produced during the pyrolysis and exits the top of the reactor with the steam. A crossover arm, fed by gravity, moves sand and char from the pyrolyzer to the second fluidized bed. This sand bed uses blown air to combust the char. The exit stream from this side of the reactor is carbon dioxide, water and ash. There is a second gravity fed crossover arm to return sand to the pyrolysis side. The recirculating action of the sand and the char is the key to the operation of the dual fluidized bed reactor.

The objective of the project was to design and construct a dual fluidized bed prototype reactor from literature information and in discussion with established experts in the field. That would be appropriate in scale and operation to measure the relative performance of the gasification of biomass and low ranked coals to produce a high quality synthesis gas with no dilution from nitrogen or combustion products.

Cold flow testing indicated that even at small scale a dual fluidized bed system could operation with sufficient inter-bed transport of the fluidizing media to allow operation of a biomass gasifier using this concept.

A working stainless steel prototype of the dual fluidized bed was constructed with all associated support systems to allow testing of the gasification of biomass and low ranked coals to produce a high quality synthesis gas with no dilution from nitrogen or combustion products.

The budget for this base project was small and just covered the construction portion of the dual fluidized bed prototype. Testing and operation of the unit will occur within future base and joint sponsored research projects. 


\section{INTRODUCTION}

There are several designs for biomass and coal gasification reactors that use multiple stages systems to avoid the requirement for expensive oxygen separation systems. By isolating pyrolysis and combustion steps, air can be used in these gasifiers without the problems associated with nitrogen dilution of the syngas products. The Taylor Energy gasifier, a gasifier in a JSR study at Western Research Institute (WRI), is a design that has certain risks in scale and operation. Dual-fluidized bed reactors, although of slightly less overall theoretical efficiency, are both proven and of simpler design. Should the Phase I of the JSR system reactor fail, the dual bed design operating at bench scale would be a stepping stone for moving the Phase II biomass gasification project forward.

The dual fluidized bed reactor is a recirculating system in which one half of the unit operates as a steam pyrolysis device for biomass. The pyrolysis occurs by introducing biomass and steam to a hot fluidized bed of inert material such as coarse sand. Syngas is produced during the pyrolysis and exits the top of the reactor with the steam. A crossover arm, fed by gravity, moves sand and char from the pyrolyzer to the second fluidized bed. This sand bed uses blown air to combust the char. The exit stream from this side of the reactor is carbon dioxide, water and ash. There is a second gravity fed crossover arm to return sand to the pyrolysis side. The recirculating action of the sand and the char is the key to the operation of the dual fluidized bed reactor.

\section{TASK OBJECTIVES}

Construct a prototype dual fluidized bed reactor for the steam/air gasification of biomass and low-grade coals. Use the prototype to determine scale-up parameters for pilot scale gasification operations.

Milestones:

- Design a dual fluidized bed prototype reactor from literature information and in discussion with established experts in the field.

- Construct the prototype reactor.

- Operate the reactor for three days in simulation, three days in shakedown mode, and 14 days under true operational conditions.

- Write a report collecting operational data and including simple modeling data for scaleup to pilot scale operations.

\section{EXPERIMENTAL}

\section{Cold Flow Model Testing}

Before constructing a stainless steel reactor system, a cold flow model was constructed in several iterations. The design and scale of the prototype was based on existing restrictions in the support hardware that would be used to operate the reactor. The electric steam boiler owned by WRI is limited to a maximum of $30 \mathrm{scfm}$ of steam. Calculations indicated that 3 to 4 inch diameter fluidized beds would be appropriate to these steam flow rates in the temperature range of 700 to $800^{\circ} \mathrm{C}$. Existing controls for airflow control would also operate well within these required flow rates. 
Polycarbonate pipe with nominal 3-inch diameter was obtained and fabricated into dual parallel, fluidized beds. The geometry of the crossover arms was investigated in several configurations using 0.75-inch diameter PVC pipe. The angle of the crossover pipes was found to be critical to the movement of sand between the beds. A high angle was necessary to allow gravity to exchange the bed materials. However, under operation, gas was found to be flowing up the crossover arms counter to the designed flow direction. Replacing the crossover pipes with a drilled block with channels stopped the counter flow of the gases, but showed very slow material exchange between the parallel beds. Small jets were introduced into the crossover arms to allow gas introduction to move material through the crossover arms more efficiently. (Figure 1)

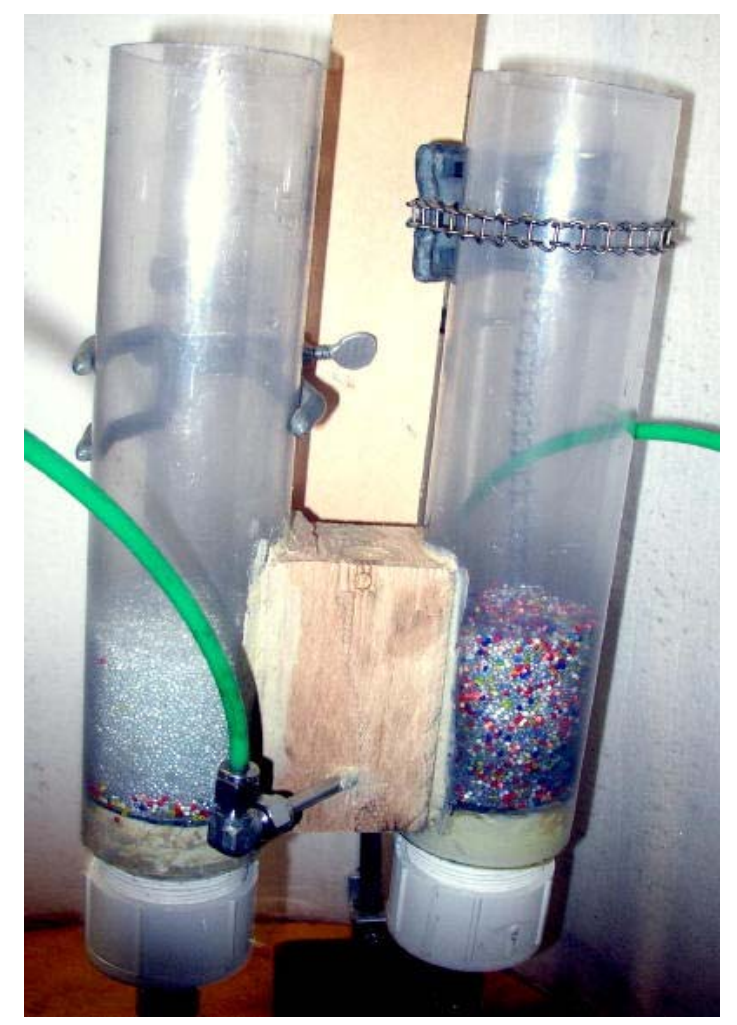

Figure 1. A cold flow model of a dual fluidized bed was produced to test transport of the fluidizing material between the two beds.

Having optimized the cold flow geometry of the dual fluidized bed reactor, different bed materials were examined in the reactors to measure fluidizing flow rates, material exchange rates, and bed heights for optimum operation. Those bed materials included coarse sand, glass beads at $2 \mathrm{~mm}$ and $3 \mathrm{~mm}$ diameter, and crushed stone. Material exchange rates were measured using one bed filled with $2 \mathrm{~mm}$ glass beads and the second bed filled with colored porcelain beads. The rate of color mixing was easily measured, and the bed exchange rate was determined to be less than 5 minutes for one full exchange, which was considered acceptable. Sand was chosen as the best bed material due to cost and performance. 


\section{Dual Fluidized Bed Prototype}

The working prototype for the dual fluidized bed reactor was constructed of stainless steel. (Figure 2) Each bed was fabricated of an 18-inch length of 3" pipe. Crossover arms were produced with an S-curve to maximize solid transport and minimize gas leakage between reactor sides. The distribution plates were fabricated from carbon steel with sixteen drilled holes each of 0.125" diameter. The combustion side of the reactor was supplied with one-inch lines for air passing through a mass flow controller and an electric gas heater. (Figure 3) The combustion exit passes through a cyclone to drop ash. There is an injection port on the combustion side vent for sampling for gas composition. The pyrolysis side of the reactor is piped to an electric boiler for steam. A flow controller determines steam flow rates. The pyrolysis exit lines pass through a knockout tank for condensate and particulates before a drying tube and an injection point for gas sampling before venting. Biomass is added using a large screw feeder located at the lower side of the pyrolysis unit. Clamshell type electric heaters are applied to each reactor side to maintain bed temperature.

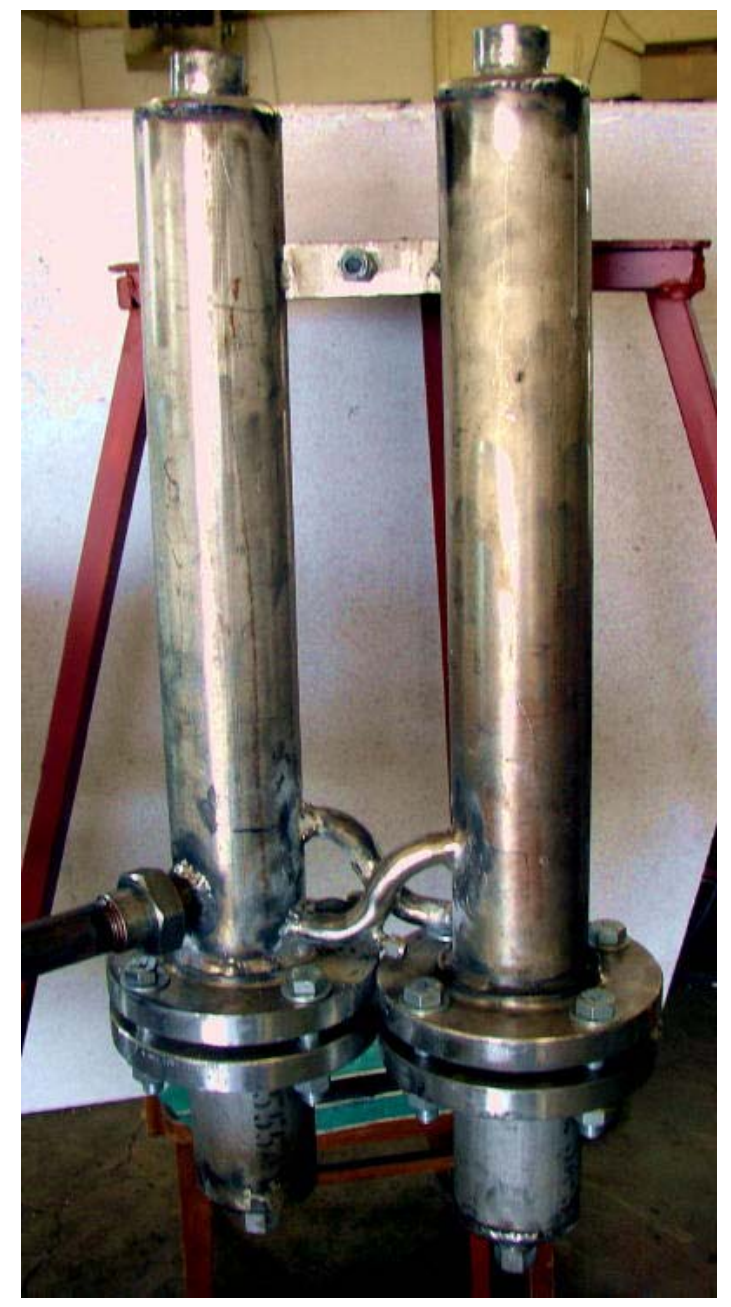

Figure 2. The stainless steel working dual fluidized bed prototype. 


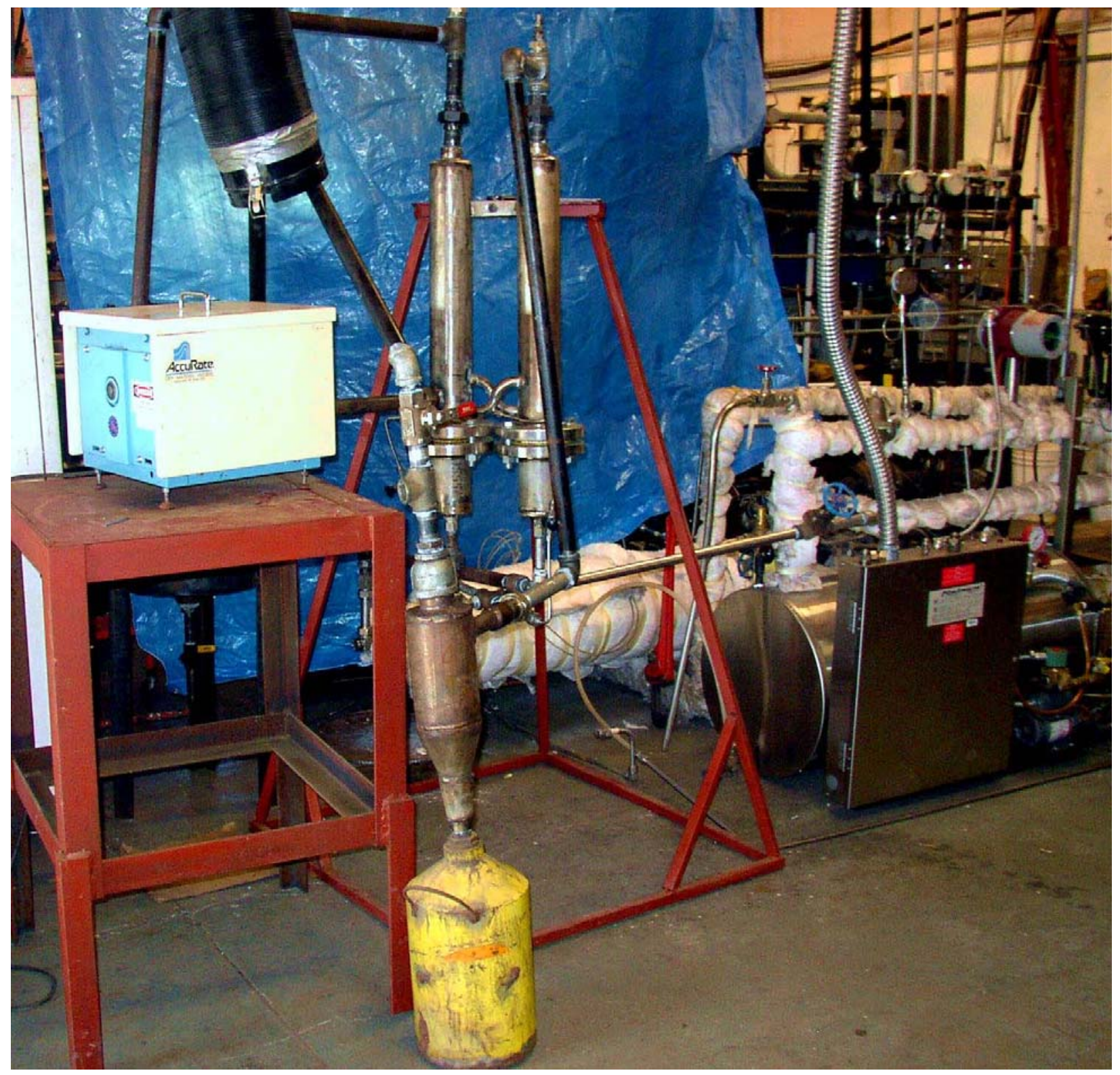

Figure 3. The working prototype and associated support systems with the heating elements removed.

\section{RESULTS AND DISCUSSION}

The cold flow model was designed and constructed to test the concept of the dual fluidized bed system. The model went through several iterations before the transportation between the two beds was sufficiently controlled. The scale of the model was critical to a consistent operation. The size of the interconnected channels and the size of the inert bed particles were directly related and an important consideration. At this small size of 3" diameter beds, even the shape of the fluidizing particles is important to predict the flow and interchange of the bed material between the two fluidizing beds. Spherical particles of $2 \mathrm{~mm}$ and $3 \mathrm{~mm}$ diameter made of glass produced good fluidizing results. Larger spherical particles required excessive 
airflow rates for consistent fluidization. Sand, while able to be fluidized, produced an excessive amount of wear and ablation loss.

Enough confidence was obtained to allow the construction of the working prototype. The stainless steel unit was designed to include all the important aspects of the cold flow model and remain simple enough to be constructed using standard machine shop techniques of fabrication. The stainless working prototype has all the necessary characteristics to perform biomass gasification testing and provide a high quality synthesis gas product free of combustion gases and nitrogen from air. The control systems for air and steam flow, biomass injection, and heat application are well scaled to the prototype size. The product handling systems are appropriate for removing any solids carried out from the fluidized beds and taking the products to a flare for disposal. Sampling ports were installed to allow analytical testing of the product gases. The device should be a good test bed for the concept and measure the relative performance of various types of biomass and low ranked coals.

The budget for this base project was small and just covered the construction portion of the dual fluidized bed prototype. Testing and operation of the unit will occur within future base and joint sponsored research projects.

\section{CONCLUSIONS}

- Cold flow testing indicated that even at small scale a dual fluidized bed system could operation with sufficient inter-bed transport of the fluidizing media to allow operation of a biomass gasifier using this concept.

- A working stainless steel prototype of the dual fluidized bed was constructed with all associated support systems to allow testing of the gasification of biomass and low ranked coals to produce a high quality synthesis gas with no dilution from nitrogen or combustion products.

\section{REFERENCES}

D. Kunii and O. Levenspiel, Fluidization Engineering, John Wiley and Sons, New York (1969) 